\title{
Do Overweight and Obese Individuals Select a "Moderate Intensity" Workload When Asked to Do So?
}

\author{
Cameron W. Hall, ${ }^{1}$ Michael E. Holmstrup, ${ }^{2}$ Jay Koloseus, ${ }^{2}$ \\ Daniel Anderson, ${ }^{1}$ and Jill A. Kanaley ${ }^{2,3}$ \\ ${ }^{1}$ Department of Medicine, SUNY Upstate Medical University, Syracuse, NY 13210, USA \\ ${ }^{2}$ Department of Exercise Science, Syracuse University, Syracuse, NY 13244, USA \\ ${ }^{3}$ Department of Nutrition and Exercise Physiology, University of Missouri, Columbia, MO 65211, USA
}

Correspondence should be addressed to Jill A. Kanaley, kanaleyj@missouri.edu

Received 16 September 2011; Revised 15 December 2011; Accepted 27 February 2012

Academic Editor: António Palmeira

Copyright (c) 2012 Cameron W. Hall et al. This is an open access article distributed under the Creative Commons Attribution License, which permits unrestricted use, distribution, and reproduction in any medium, provided the original work is properly cited.

\begin{abstract}
The purpose of this study was (1) to determine if overweight/obese individuals (age 26-50 y) would self-select moderate exercise intensity when asked to do so and (2) to determine how this self-selected workload compared to exercising at a workload (60\% peak aerobic capacity) that is known to provide cardioprotective health benefits. Oxygen consumption $\left(\mathrm{VO}_{2}\right)$ and energy expenditure were measured in $33 \mathrm{men} /$ women $\left(\mathrm{BMI} \geq 27 \mathrm{~kg} / \mathrm{m}^{2}\right)$ who completed two $30 \mathrm{~min}$ walking bouts: (1) self-selected walking pace on an indoor track and (2) prescribed exercise pace $\left(60 \% \mathrm{VO}_{2}\right.$ peak) on a treadmill. The data revealed that (1) the prescribed intensity was $6 \%$ higher than the self-selected pace and elicited a higher energy expenditure $(P<0.05)$ than the self-selected pace $(+83 \mathrm{~kJ})$; (2) overweight subjects walked at a slightly lower percentage of $\mathrm{VO}_{2}$ peak than the obese subjects $(P<0.05)$; (3) men walked at a lower percentage of $\mathrm{VO}_{2}$ peak than the women $(P<0.05)$. In conclusion when asked to walk at a moderate intensity, overweight/ obese individuals tended to select a lower workload in the "moderate intensity" range which could be maintained for 30 min; however, a higher intensity which would be more cardioprotective could not be maintained for 30 min by most individuals.
\end{abstract}

\section{Introduction}

Studies have shown that 30 minutes of moderate intensity exercise can confer health benefits if performed on most days of the week ( 5 days/wk) $[1,2]$. These benefits include weight maintenance, weight loss [3], cardiovascular risk management $[4,5]$, and the avoidance of metabolic dysfunction such as type 2 diabetes [6]. Further, more than $30 \mathrm{~min}$ of physical activity a day are necessary for formerly obese individuals to maintain weight loss [7]. Success in obtaining improvements in these health outcomes often occurs because the exercise regimen is carefully controlled in a supervised setting where specific directions are provided [7-9].

As the population has become more obese, numerous guidelines have been established to help the lay public understand the amount of activity that should be incorporated into their lifestyle. For example, the 2008 Physical Activity Guidelines for Americans states that people should participate in
"150 minutes of moderate-intensity aerobic activity every week" (p. vi), which would be approximately 30 minutes of fast walking five days a week $[2,10]$. Sedentary individuals, however, may misinterpret the term moderate intensity activity, and their efforts to increase their physical activity levels may result in insufficient workloads for cardioprotection, glucose control, and weight loss and maintenance. Previous research concerned with self-selected exercise pace has used descriptors such as "walk briskly" or "preferred pace" [11-14] but have not examined the pace selected when subjects are told to walk at a "moderate intensity". Yet, "moderate intensity" is the terminology of the physical activity guidelines.

Thus, the purpose of this study was to determine the workload sedentary overweight and obese individuals would self-select when asked to walk at a "moderate intensity". Since exercise at intensities greater than $60 \%$ peak oxygen consumption $\left(\mathrm{VO}_{2}\right.$ peak) is associated with more health benefits 
[15], we compared the self-selected pace to a prescribed pace $\left(60 \% \mathrm{VO}_{2}\right.$ peak). We selected this workload because it was at the low end of the vigorous exercise range, is known to confer health benefits beyond just weight loss, and we anticipated that this intensity would be tolerable by our sedentary participants [16]. We examined the potential differences in heart rate (HR), ratings of perceived exertion (RPE), and energy expenditure at the prescribed versus self-selected "moderate intensity" exercise. Further, we determined if there was a relationship between the self-selected exercise intensity and adiposity or aerobic fitness. We hypothesized that most individuals would self-select a workload at the low end of the moderate intensity exercise pace, when required to walk for $30 \mathrm{~min}$. We further hypothesized that this workload would result in a lower energy expenditure and lower RPE than when the exercise was at an exercise intensity know to confer health benefits.

\section{Methods}

2.1. Subjects. Thirty-three overweight and obese individuals (age 30-50 y) were recruited. Inclusion criteria for the study were a body mass index (BMI) greater than $25 \mathrm{~kg} / \mathrm{m}^{2}$, nondiabetic status, not on $\beta$-blockers, no known cardiovascular disease, no metabolic disorders, no orthopedic limitations and currently not participating in a regular exercise program or coached/guided physical training. All subjects were initially screened by a detailed medical history questionnaire before consideration for the study. All participants were required to complete an informed consent document, approved by the University Institutional Review Board. This study meets the ethical standards of the journal [17].

2.2. Experimental Design. All subjects completed 3 visits which included an exercise stress test, a 30 min submaximal walk at a self-selected moderate intensity pace and a $30 \mathrm{~min}$ submaximal walk at a $60 \%$ of $\mathrm{VO}_{2}$ peak (prescribed pace). This workload was selected because it is at the low end of the vigorous exercise intensity workload and is known to provide cardioprotective benefits [15]. The submaximal visits were not presented in a randomized fashion because of the potential for learning the ideal walking intensity during the prescribed exercise intensity condition. These visits were a minimum of $72 \mathrm{~h}$ apart and no longer than 2 weeks apart.

2.3. Exercise Stress Test. Each subject walked on a Quinton Treadmill (Bothell, Washington), and a modified walking protocol was utilized that started at $2.5 \mathrm{mph}$ and $0 \%$ grade [18]. Briefly, an increasing workload was administered by initially increasing speed in increments of $0.5 \mathrm{mph}$ per stage until $3.5 \mathrm{mph}$ was achieved. Thereafter, increases in grade of $2.5 \%$ per stage were administered until volitional fatigue [19]. At the end of each stage, a rating of perceived exertion (RPE) on a scale of 6-20 was collected from the subject [20]. The American College of Sports Medicine (ACSM) guidelines were followed to establish if a physician needed to be present [21]. During exercise, expired gases were collected and analyzed for volume, $\mathrm{O}_{2}$ and $\mathrm{CO}_{2}$ content using a
Cosmed Quark b4 Metabolic Analyzer (Rome, Italy) that was calibrated prior to each test. Oxygen consumed $\left(\mathrm{VO}_{2}\right)$ and $\mathrm{CO}_{2}$ produced $\left(\mathrm{VCO}_{2}\right)$ were calculated. Heart rate $(\mathrm{HR})$ was collected continuously with a Polar Heart Rate Monitor (Polar Electro, Lake Success, NY) throughout the study. Criteria for a successful test were matched in accordance with the ACSM [22].

2.4. Body Composition. Body composition was assessed using air-displacement plethysmography (Life Measurement, Inc. Concorde, CA) and the test was administered according to the manufacture's guidelines. Height and weight were measured without shoes on prior to testing using a Healthometer (Sunbeam Products Inc, Boca Raton, FL). Body mass index was calculated as weight $(\mathrm{kg}) /$ height $\left(\mathrm{m}^{2}\right)$. Subjects were asked to wear the same clothing on each visit.

2.5. Self-Selected Submaximal Exercise Test. During the second visit, subjects were instructed to walk at a "moderate intensity" around an indoor track for thirty minutes. Subjects self-selected the pace they wanted to utilize for the 30 minutes of exercise and received encouragement to keep walking but were given no further directions than to walk at a "moderate intensity". We calculated the distance travelled on the track to determine walking speed. Subjects were not given feedback on their walking speed. Time per lap was monitored with a stopwatch (Timex Ironman Marathon Stopwatch, Timex, N. Little Rock, AR). Speed varied somewhat in a given lap, but there were no significant differences in the lap times documented during the walk for each lap (data not shown). In addition, no significant change in $\mathrm{VO}_{2}$ was observed between laps. During this test, the subject donned a harness that carried the K4 Cosmed portable metabolic analyzer (Rome, Italy) which was calibrated before each test. HR was measured continuously using Polar Heart Rate technology. Ratings of perceived exertion were collected every five minutes of exercise. At the end of thirty minutes, total distance covered was measured in order to calculate average speed.

2.6. Prescribed Exercise at $60 \% \mathrm{VO}_{2}$ Peak. The subjects walked on a treadmill for 30 minutes at $\sim 60 \% \mathrm{VO}_{2}$ peak. The exercising pace was selected based on the performance on the $\mathrm{VO}_{2}$ peak test from the first visit. Wearing the same $\mathrm{K} 4$ apparatus as the track visit, the subject walked on a Quinton Treadmill while expired gases were collected. Heart rate was measured continuously, and again RPE was ascertained at the end of every five minutes.

2.7. Data Analysis. The breath by breath $\mathrm{VO}_{2}$ data were averaged into 15 second intervals. The $\mathrm{VO}_{2}$ peak was considered the highest value achieved at the end of the test while meeting all other ACSM guidelines for a successful stress test [22]. The calculated $\mathrm{VO}_{2}$ from the track and treadmill evaluations was averaged into one-minute intervals and from these data energy expenditure per minute was calculated [23-26], as well as per $\mathrm{kg}$ fat free mass (FFM). Total expenditure for the duration of exercise of both visits was then calculated as the 
TABle 1: Descriptive characteristics of the subject separated by gender.

\begin{tabular}{lcc}
\hline & Females $(n=24)$ & Males $(n=9)$ \\
& $(16$ obese/8 overweight $)$ & $(5$ obese/4 overweight $)$ \\
\hline Age $(\mathrm{yr})$ & $41.7 \pm 1.5$ & $43.3 \pm 2.2$ \\
& $(26-50)$ & $(30-50)$ \\
Height $(\mathrm{cm})$ & $164.5 \pm 1.2$ & $180.7 \pm 1.7^{*}$ \\
& $(153-175)$ & $(173-191)$ \\
Weight $(\mathrm{kg})$ & $89.2 \pm 2.9$ & $101.6 \pm 5.6^{*}$ \\
& $(69-123)$ & $80-137)$ \\
Body mass & $33.1 \pm 1.1$ & $31.1 \pm 1.3$ \\
index $\left(\mathrm{kg} / \mathrm{m}^{2}\right)$ & $(27-48)$ & $(27-40)$ \\
& $35.6 \pm 2.0$ & $26.3 \pm 2.3^{*}$ \\
\% body fat & $(27-48)$ & $(20-48)$ \\
& $27.0 \pm 1.2$ & $37.3 \pm 2.4^{*}$ \\
VO peak & $(18-42)$ & $(27-45)$ \\
\hline
\end{tabular}

${ }^{*} P<0.05$ between genders. Mean \pm standard error (range of values).

sum of the one-minute averages. Both total $\mathrm{kJ}$ and steady state values are presented. Steady state values were used for the calculation of average $\mathrm{VO}_{2}$ and $\mathrm{HR}$ responses to exercise in order to accurately represent level of workload accomplished. Also from the $\mathrm{VO}_{2}$ data the MET level was calculated with $3.5 \mathrm{~mL} / \mathrm{kg} / \mathrm{min}$ equaling $1 \mathrm{MET}$ [22].

2.8. Statistical Analysis. The data were tested for normality using the Shapiro-Wilk test of normality. A paired $t$-test was performed to compare variables from the track and treadmill visit. When comparing for gender differences, a 2 (male versus female) X treatment (self-selected versus prescribed) ANOVA with repeated measures or 2 (obese versus overweight) $\mathrm{X}$ treatment (self-selected versus prescribed) ANOVA with repeated measures was employed. Using the statistical package for the social sciences (SPSS) for Windows (Chicago, IL ver. 17), all variables were expressed as mean \pm standard error. A Pearson correlation was used to determine the relationship between the differences in energy expenditure and other measured variables, as well as between walking speed and descriptive subject variables. Those descriptive variables that were positively associated with walking speed were put into a linear regression analysis using the enter method to find the best predictor of walking speed. This method allows the entry of variables into the analysis and allows the program to select the order of entering the variable into the model. Significance was accepted at a preset alpha $=$ 0.05 .

\section{Results}

Thirty-three subjects volunteered for this study, 24 females and 9 males. The BMI ranged from $27-40 \mathrm{~kg} / \mathrm{m}^{2}$, and of the 33 subjects 21 subjects were obese and 12 were overweight (Table 1$)$. The men and women were similar in age $(\sim 42.5 \mathrm{y})$ but the men were significantly $(P<0.05)$ heavier, taller, and had a greater percent body fat. The men were slightly more fit $(P<0.05)$ than the women.

Total energy expenditure for the prescribed walking was significantly greater than the energy expenditure for selfselected walking pace $(955.7 \pm 39.2 \mathrm{~kJ}$ versus $872.7 \pm 39.9 \mathrm{~kJ}$, $P<0.01$, resp.), resulting in $83 \mathrm{KJ}$ more being expended at the prescribed pace than in the self-selected pace. The men had a greater energy expenditure than the women (self-selected: males $1057.7 \pm 51.0 \mathrm{~kJ}$ and females $803.4 \mathrm{~kJ} \pm 26.4 \mathrm{~kJ}-$ prescribed: males $1218.6 \pm 35.1 \mathrm{~kJ}$ and females $857.1 \pm$ $22.3 \mathrm{~kJ}, P<0.01$ ), and there were no differences in total energy expenditure between the obese and overweight subjects. Adjusting the data for fat free mass did not alter the findings, and the prescribed walking pace $(10.4 \pm 0.3 \mathrm{~kJ} / \mathrm{kg}$ $\mathrm{FFM} / \mathrm{min}$ ) elicited a higher rate of energy expenditure than the self-selected pace $(9.4 \pm 0.3 \mathrm{~kJ} / \mathrm{kg} \mathrm{FFM} / \mathrm{min}, P<0.05$; Figure 1). However, men had a higher energy expenditure $(\mathrm{kJ} / \mathrm{kg} \mathrm{FFM} / \mathrm{min})$ than the women $(P<0.01)$, and the overweight subjects had a slightly higher energy expenditure than the obese subjects $(P<0.05)$.

Self-selected exercise resulted in a workload of $52 \%$ of $\mathrm{VO}_{2}$ peak versus $58 \%$ of $\mathrm{VO}_{2}$ peak for the prescribed exercise $(P<0.05)$. The mean prescribed $\% \mathrm{VO}_{2}$ is lower than we had targeted as many of the subjects could not complete 30 min of exercise at $\sim 60 \% \mathrm{VO}_{2}$ peak. The overweight subjects walked at a lower percentage of $\mathrm{VO}_{2}$ peak than the obese subjects $(P<0.05)$, regardless if the exercise pace were self-selected or prescribed. The \%HR max for the 30 min of prescribed and self-selected walking were not significantly different (selfselected: $75.1 \pm 11.2 \mathrm{~b} / \mathrm{min}$; prescribed: $75.5 \pm 7.9$, Table 2 ). Mean RPE values for the prescribed walking was slightly greater than for the self-selected walking pace (self-selected: mean $11.3 \pm 0.2$, range $8-13$ versus prescribed: mean $12.5 \pm$ 0.3 , range 11-15, Table 2); no sex differences were observed. Converting the work intensity to METs revealed no differences until 15 minutes of exercise where the MET levels significantly increased and the self-selected intensity was less than the prescribed intensity, and remained lower through the remaining 30 minutes (self-selected $4.2 \pm 0.2$, prescribed $4.9 \pm 0.2$ METs, $P<0.01)$.

An association was found between the difference in energy expended between the prescribed and self-selected walking and $\mathrm{VO}_{2}$ peak $(r=0.53, P<0.01$, Figure $2(\mathrm{a}))$, and adjusting for sex did not alter this finding. The best predictor of the self-selected walking speed in this cohort of subjects was fat mass which explained $32 \%$ of the variability $(\beta$ coefficient $=-0.564, R^{2}=0.32, P<0.001$, Figure 2(b)). Fitness, age, height, and sex were not significant predictors of walking speed in this cohort of subjects.

\section{Discussion}

Although the current physical activity recommendation for health is to accumulate at least 30 min of moderate intensity physical activity daily, the interpretation of moderate can vary considerably between individuals. A misconception of the term "moderate" may potentially result in the selected physical activity workload not being in an appropriate 
TABLE 2: Ratings of perceived exertion and \% max heart rate for the self-selected and prescribed walking pace for both the males and females.

\begin{tabular}{lcccc}
\hline Variable & & Female & Males & Total \\
\hline RPE & Self-selected & $11.7 \pm 0.2$ & $10.1 \pm 0.3$ & $11.3 \pm 0.2$ \\
& Prescribed pace & $12.6 \pm 0.4^{* *}$ & $12.2 \pm 0.4^{* *}$ & $12.5 \pm 0.3$ \\
\hline$\%$ max HR & Self-selected & $78.0 \pm 1.9$ & $67.9 \pm 1.9$ & $75.1 \pm 2.0$ \\
& Prescribed pace & $77.4 \pm 1.4$ & $70.5 \pm 1.4$ & $75.5 \pm 1.4$ \\
\hline
\end{tabular}

Mean \pm SE. $* P<0.05$ between testing days, $* * P<0.001$ between testing days.

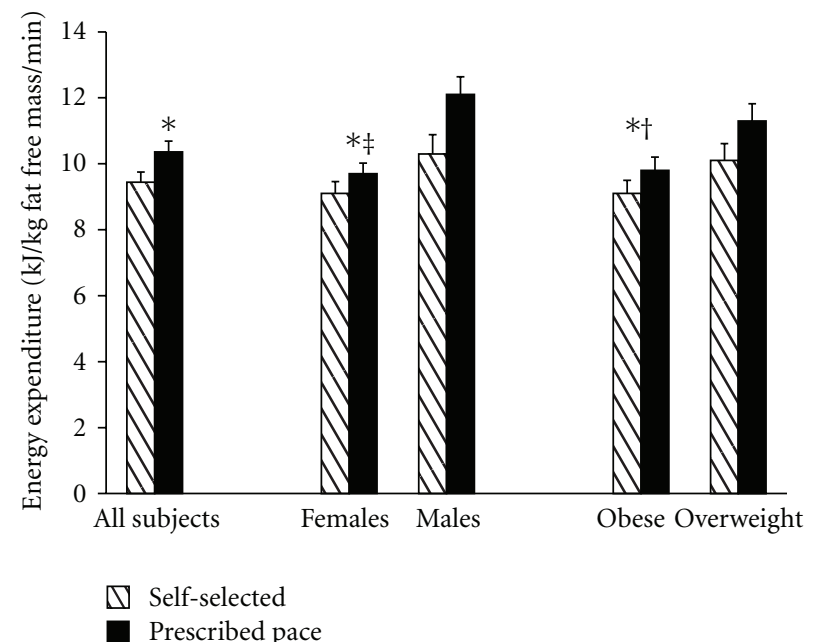

(a)

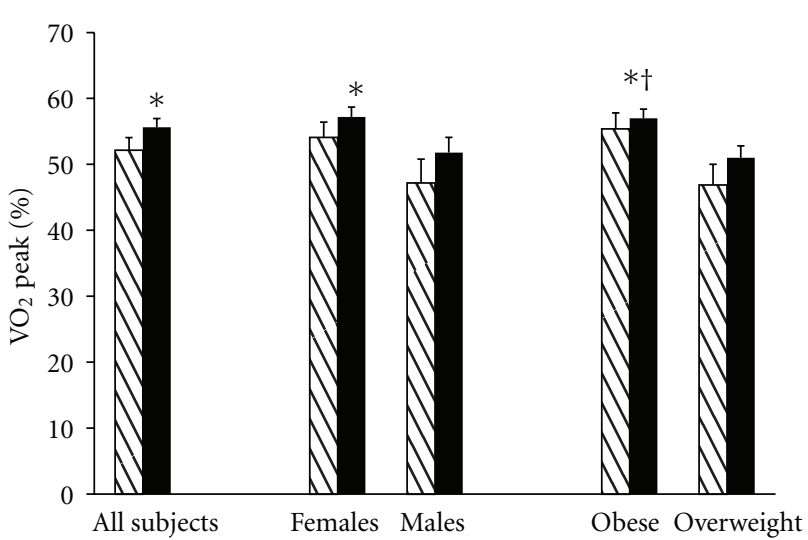

\S Self-selected

Prescribed pace

FIGURE 1: The rate of energy expenditure (a) and percent peak oxygen consumption $\left(\mathrm{VO}_{2}\right.$ peak) (b) for the self-selected walking pace and the prescribed walking pace for 33 overweight subjects during 30 minutes of exercise. ${ }^{*} P<0.05$ between the self-selected and prescribed pace; ${ }^{\dagger} P<0.05$ between obese and overweight subjects; ${ }^{\ddagger} P<0.01$ between men and women.

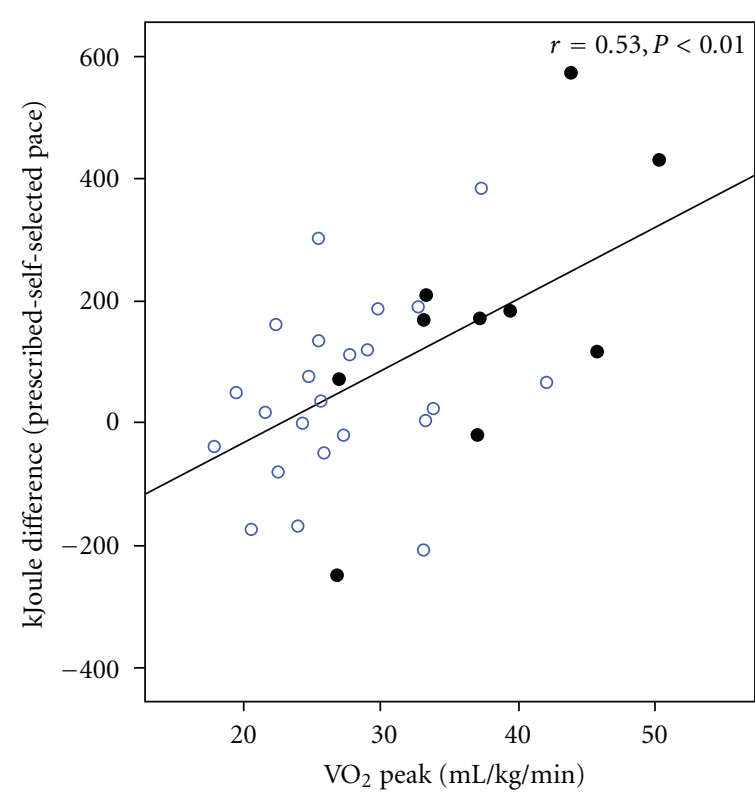

(a)

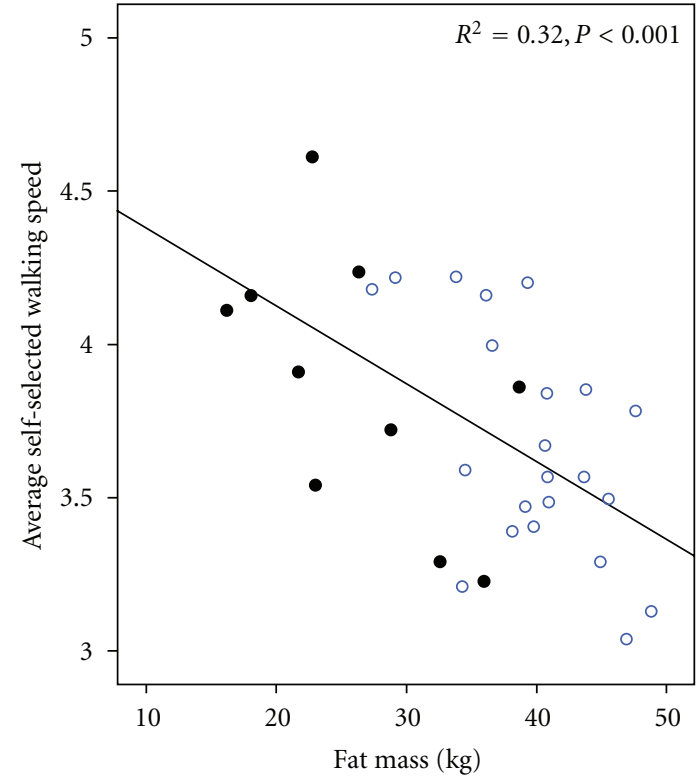

(b)

FIGURE 2: (a) The association between $\mathrm{VO}_{2}$ peak and the difference in energy expended between the prescribed and self-selected walking pace and (b) the association between self-selected walking speed and fat mass. $\bigcirc$ Women, Men. 
intensity range to be cardioprotective. The present study revealed the following: (1) the self-selected pace $\left(52 \% \mathrm{VO}_{2}\right.$ peak) was in the range that is defined as moderate (40$59 \% \mathrm{VO}_{2}$ peak), (2) the $\mathrm{HR}$ response was similar between experimental conditions yet, (3) RPE was greater in the prescribed bout than when the exercise was self-selected, and (4) a lower energy expenditure occurred with the self-selected workload than with the prescribed workload. These findings indicate that when participants are allowed to self-select exercise intensity, the workload would meet the ACSM standards and potentially would be effective in increasing cardiorespiratory fitness; however, the workload may not be adequate to provide other health benefits [27].

Our subjects were able to select a workload in the range of moderate intensity when asked; however, when the subjects were asked to increase the workload slightly to the high end of the moderate intensity range ( $\sim 58 \%$ of $\mathrm{VO}_{2}$ peak), $68 \%$ of the subjects could not complete our prescribed workload, and the workload had to be reduced after 15-20 min of exercise. In addition, this reduction in workload may have resulted in slightly smaller differences in energy expenditure between the self-selected and prescribed pace. Further the obese individuals worked at a higher $\% \mathrm{VO}_{2}$ peak than the overweight subjects, in agreement with findings by Mattsson et al. [14]. Possibly, obese individuals receive more information on the appropriate exercise pace or possibly they have a smaller $\mathrm{VO}_{2}$ reserve than an overweight individual thus working at a higher percentage of their aerobic capacity.

The inability to complete $30 \mathrm{~min}$ at the higher intensity parallels the findings of Ekkekakis and Lind [28] who noted that imposing a speed that is just $10 \%$ higher than what overweight women self-selected led to a decline in reported pleasure and decreased affective responses. This may explain why studies in controlled settings obtain more dramatic effects on health variables $[29,30]$ than when subjects participate in unsupervised exercise. Moreover, other studies have shown that subjects told to exercise at a "brisk pace" and not at their "preferred pace" the exercise intensity increased to levels well above the minimum of the recommended range $[11,12]$. Hence, this provides further evidence that the descriptor used in the physical activity recommendation must be carefully considered.

Although there was no difference in the exercise HR between the self-selected and prescribed trial, RPE increased with the prescribed workload, indicating cardiophysiological tolerance but increased perception of the workload [31]. This finding highlights that there may be a mismatch between perceived-exertion and physiological responses of Borg's model of effort continua in sedentary obese individuals. More specifically, a higher intensity of exercise is less pleasurable and enjoyable, thus perceived as greater exertion. Lind et al. [13] have shown that declines in affective valence and consistent ratings of perceived exertion are found when subjects are at an exercise intensity that exceeds the transition across the lactate threshold. We did not measure the lactate threshold in the present study, but a workload at $60 \% \mathrm{VO}_{2}$ peak most likely would have been at or above their lactate threshold, based on other studies in sedentary individuals [32]. An RPE of 13 is considered to be approximately the lactate threshold
[33] so our subjects as well as those subjects from the other studies kept their self-selected paces below the lactate threshold. Further it was also observed that as subject fitness increased, as represented by $\mathrm{VO}_{2}$ peak, there was an increase in the difference in energy expended between walking trials (Figure 2).

The workload selected in the moderate range may reduce CHD risk factors or all-cause mortality, but this workload may be inadequate for weight loss or to improve other health outcomes. From a meta-analysis conducted by Swain and Franklin [15] greater cardioprotective benefits were obtained with an increase in either the relative or absolute intensity of exercise. In fact, a faster walking speed was associated with a reduced CHD risk, independent of the total energy expenditure $[15,34]$. One study found that only physical activities at intensities $>4.5$ METs were associated with a decreased incidence of hypertension and reduced all-cause mortality [35]. Our self-selected pace was below this MET value while the prescribed pace was above this value. Additionally more favorable risk profiles occur with vigorous activity compared to moderate-intensity physical activity. Swain and Franklin [15] reported that 3 studies indicated that groups exercising at the highest intensity (65-75\% of $\left.\mathrm{VO}_{2} \max \right)$ experienced a decrease in diastolic blood pressure, but the group that exercised at lower intensities (45-57\% $\mathrm{VO}_{2}$ max) did not. Likewise improvements in glucose control and insulin sensitivity only occurred at vigorous intensities $\left(65-70 \% \mathrm{VO}_{2} \max \right)$ but not at moderate intensities $\left(40-55 \% \mathrm{VO}_{2} \mathrm{max}\right)$. In general, greater relative intensities result in greater improvements in aerobic fitness and selected CHD risk factors. Other epidemiologic studies have shown that each 1-MET increases in exercise capacity confers an $8-17 \%$ reduction in cardiovascular and all-cause mortality $[15,36,37]$. A review of the literature has shown that in low-fit subjects a minimal intensity of $30 \% \mathrm{VO}_{2}$ reserve is needed, while in high-fit subjects exercise above $40 \% \mathrm{VO}_{2}$ reserve is needed to improve cardiovascular fitness [27]. In the present study only the prescribed workload was adequate to provide some of these health benefits and still many subjects could not complete this workload; this agrees with previous research [31].

In the self-selected walking pace, our subjects walked at a lower perceived exertion $(\sim 11)$ than when the exercise was prescribed. This RPE was slightly higher than that reported by Pintar et al. [38], who noted that both normal weight and overweight women ( 20 yr old) selected a preferred walking intensity that resulted in the selection of a similar $\mathrm{RPE}(\sim 10)$ for a 15 minute trial. The women had a slightly higher RPE for the task than men, and more closely obtained the desirable exercise intensity. Mattsson et al. [14] reported that normal weight subjects use about $36 \% \mathrm{VO}_{2}$ max when walking at a self-selected comfortable pace. Similarly Huebschmann et al. [39] reported that during cycle ergometer exercise that individuals with type 2 diabetes perceived the work to be more difficult (higher RPE) than obese individuals, even when adjusted for the relative work intensity. The higher self-selected RPE in our study may be because the selfselected pace on the track was their first testing day and the subjects may have been slightly anxious. In contrast to our finding, Dasilva et al. reported a higher perceived exertion 
and a less positive affective valence in treadmill walking than during over ground walking [40].

The best predictor of walking speed in the present study was fat mass which explained $32 \%$ of the variability in selfselected speed; fitness did not significantly explain the variability in walking speed. These data support an inverse relationship between adiposity and self-selected walking speed and suggested that obese individuals may choose lower walking speed in their daily exercise regimens as compared to lean individuals. Pintar [38] reported that fitness but not body weight influenced preferred exercise intensity. Discrepancies in these findings are most likely due to the fact that they used college-aged women, while our subject pool was more middle-aged and both men and women were included. Furthermore, it is well established in the literature that the addition of nonmetabolically active weight increases energy expenditure proportional to the weight [41]. Thus individuals carrying more body fat would most likely perceive the exercise to be more difficult.

A potential limitation of the present study is that visits two and three could not be randomized due to the learning effect that the prescribed exercise visit may have had on the self-selected walking pace. By allowing our subjects to walk on a track, this enabled the subject to have normal variance in speed and be blinded to pace by walking on the track during the second visit. All visits were separated by at least three days to avoid the influence of fatigue and muscle soreness; no subject was tested a second time if they still had muscle soreness following the first study day. There is also the possible confounding factor that the self-selected pace was measured on a track, while the prescribed pace was on the treadmill. We have previously shown that energy expenditure does not differ when walking on the track or treadmill at similar speeds [42]; however other investigators have found a higher metabolic cost of treadmill walking $[40,43]$ and a higher perceived exercise and a less positive affective valence [40].

In this paper we have only cited the ACSM and AHA guidelines of "150 minutes of moderate intensity aerobic activity every week" (p. vi), which would equal 30 minutes of walking five days a week. However, it should be acknowledged that there are other guidelines that have been published (e.g., the Institute of Medicine, World Health Organization, USDA, etc.) that recommend for the prevention of weight gain at least 60 min of moderate physical activity daily is needed and for weight loss/weight maintenance this may need to be as high as 60-90 min daily [7]. Individuals wishing to lose weight may have difficulty not only completing 30 minutes of exercise but also completing longer durations which have been shown to be necessary for successful weight loss [7]. Further it should be noted that although we collected the data as one exercise bout for 30 minutes, there has been considerable research that has indicated that the 30 minutes (or 60 minutes) can be accumulated using multiple short bouts of exercise [44], which may be a more efficient strategy for individuals who are incorporating higher intensity physical activity into their day or need to put in $60-90$ minutes/day.

According to the recommendations from ACSM and the American Heart Association, individuals should participate in at least 150 minutes a week of moderate intensity cardiovascular exercise or 75 minutes a week of vigorous-intensity aerobic physical activity. Previous literature has indicated that more vigorous exercise is needed for many of the health-related benefits. Despite "moderate exercise" being a nebulous term, which can be widely interpreted, these preliminary data show that subjects self-selected a workload in the middle of the moderate range, but less than the workload ( $>60 \% \mathrm{VO}_{2}$ peak-high end of the moderate intensity range) that may be necessary to confer health benefits beyond just weight loss [15]. Yet many individuals cannot maintain that workload for 30 minutes. This finding potentially has broad implications to practitioners in giving physical activity recommendations, as workload recommendations at the high end of the moderate range may result in a decreased in adherence. Further men and overweight subjects tended to select lower workloads when asked to exercise at a moderate pace.

\section{References}

[1] R. R. Pate, M. Pratt, S. N. Blair et al., "Physical activity and public health: a recommendation from the centers for disease control and prevention and the american college of sports medicine," Journal of the American Medical Association, vol. 273, no. 5, pp. 402-407, 1995.

[2] Centers for Disease Control and Prevention, "Physical Activity Guidelines for Americans,” 2008, http://www.cdc.gov/physicalactivity/everyone/guidelines/adults.html.

[3] K. Ohkawara, S. Tanaka, M. Miyachi, K. Ishikawa-Takata, and I. Tabata, "A dose-response relation between aerobic exercise and visceral fat reduction: systematic review of clinical trials," International Journal of Obesity, vol. 31, no. 12, pp. 1786-1797, 2007.

[4] Y. Goldberg, M. Boaz, Z. Matas, I. Goldberg, and M. Shargorodsky, "Weight loss induced by nutritional and exercise intervention decreases arterial stiffness in obese subjects," Clinical Nutrition, vol. 28, no. 1, pp. 21-25, 2009.

[5] C. D. Lee, X. Sui, and S. N. Blair, "Combined effects of cardiorespiratory fitness, not smoking, and normal waist girth on morbidity and mortality in men," Archives of Internal Medicine, vol. 169, no. 22, pp. 2096-2101, 2009.

[6] J. F. Brun, S. Bordenave, J. Mercier, A. Jaussent, M. C. Picot, and C. Préfaut, "Cost-sparing effect of twice-weekly targeted endurance training in type 2 diabetics: a one-year controlled randomized trial," Diabetes and Metabolism, vol. 34, no. 3, pp. 258-265, 2008.

[7] J. M. Jakicic, B. H. Marcus, W. Lang, and C. Janney, "Effect of exercise on 24-month weight loss maintenance in overweight women," Archives of Internal Medicine, vol. 168, no. 14, pp. 1550-1559, 2008.

[8] I. Giannopoulou, L. L. Ploutz-Snyder, R. Carhart et al., "Exercise is required for visceral fat loss in postmenopausal women with type 2 diabetes," Journal of Clinical Endocrinology and Metabolism, vol. 90, no. 3, pp. 1511-1518, 2005.

[9] R. Ross, I. Janssen, J. Dawson et al., "Exercise-induced reduction in obesity and insulin resistance in women: a randomized controlled trial," Obesity Research, vol. 12, no. 5, pp. 789-798, 2004.

[10] W. L. Haskell, I. M. Lee, R. R. Pate et al., "Physical activity and public health: updated recommendation for adults from the american college of sports medicine and the american 
heart association," Circulation, vol. 116, no. 9, pp. 1081-1093, 2007.

[11] C. F. Fitzsimons, C. A. Greig, D. H. Saunders et al., "Responses to walking-speed instructions: implications for health promotion for older adults," Journal of Aging and Physical Activity, vol. 13, no. 2, pp. 172-183, 2005.

[12] E. M. Murtagh, C. A. G. Boreham, and M. H. Murphy, "Speed and exercise intensity of recreational walkers," Preventive Medicine, vol. 35, no. 4, pp. 397-400, 2002.

[13] E. Lind, R. R. Joens-Matre, and P. Ekkekakis, "What intensity of physical activity do previously sedentary middle-aged women select? Evidence of a coherent pattern from physiological, perceptual, and affective markers," Preventive Medicine, vol. 40, no. 4, pp. 407-419, 2005.

[14] E. Mattsson, U. E. Larsson, and S. Rossner, "Is walking for exercise too exhausting for obese women?" International Journal of Obesity and Related Metabolic Disorders, vol. 21, no. 5, pp. 380-386, 1997.

[15] D. P. Swain and B. A. Franklin, "Comparison of cardioprotective benefits of vigorous versus moderate intensity aerobic exercise," American Journal of Cardiology, vol. 97, no. 1, pp. 141-147, 2006.

[16] G. E. Duncan, S. D. Anton, S. J. Sydeman et al., "Prescribing exercise at varied levels of intensity and frequency: a randomized trial," Archives of Internal Medicine, vol. 165, no. 20, pp. 2362-2369, 2005.

[17] D. J. Harriss and G. Atkinson, "Ethical standards in sport and exercise science research," International Journal of Sports Medicine, vol. 30, no. 10, pp. 701-702, 2009.

[18] T. Baynard, R. M. Franklin, S. Goulopoulou, R. Carhart, and J. A. Kanaley, "Effect of a single versus multiple bouts of exercise on glucose control in women with type 2 diabetes," Metabolism, vol. 54, no. 8, pp. 989-994, 2005.

[19] J. A. Kanaley, S. Goulopoulou, R. M. Franklin et al., "Plasticity of heart rate signalling and complexity with exercise training in obese individuals with and without type 2 diabetes," International Journal of Obesity, vol. 33, no. 10, pp. 1198-1206, 2009.

[20] G. A. Borg, "Psychological basis of physical exertion," Medicine \& Science in Sports \& Exercise, vol. 14, pp. 377-380, 1982.

[21] A.C.o.S. Medicine, ACSM's Guidelines for Exercise Testing and Prescription, Lippencott Williams \& Wilkens, Hagerstown, Md, USA, 8th edition, 2009.

[22] American College of Sports Amedicine, ACSM's Guidelines for Exercise Testing and Prescription, Lippincott Williams \& Williams, Philadelphia, Pa, USA, 2009.

[23] Y. H. Chang and R. Kram, "Metabolic cost of generating horizontal forces during human running," Journal of Applied Physiology, vol. 86, no. 5, pp. 1657-1662, 1999.

[24] C. T. Farley and T. A. McMahon, "Energetics of walking and running: insights from simulated reduced- gravity experiments," Journal of Applied Physiology, vol. 73, no. 6, pp. 27092712, 1992.

[25] R. Kram and C. R. Taylor, "Energetics of running: a new perspective," Nature, vol. 346, no. 6281, pp. 265-267, 1990.

[26] T. M. Lejeune, P. A. Willems, and N. C. Heglund, "Mechanics and energetics of human locomotion on sand," Journal of Experimental Biology, vol. 201, no. 13, pp. 2071-2080, 1998.

[27] D. P. Swain and B. A. Franklin, " $\mathrm{VO}_{2}$ reserve and the minimal intensity for improving cardiorespiratory fitness," Medicine and Science in Sports and Exercise, vol. 34, no. 1, pp. 152-157, 2002.
[28] P. Ekkekakis and E. Lind, "Exercise does not feel the same when you are overweight: the impact of self-selected and imposed intensity on affect and exertion," International Journal of Obesity, vol. 30, no. 4, pp. 652-660, 2006.

[29] S. Lee, J. L. Kuk, L. E. Davidson et al., "Exercise without weight loss is an effective strategy for obesity reduction in obese individuals with and without type 2 diabetes," Journal of Applied Physiology, vol. 99, no. 3, pp. 1220-1225, 2005.

[30] R. Ross, I. Janssen, J. Dawson et al., "Exercise-induced reduction in obesity and insulin resistance in women: a randomized controlled trial," Obesity Research, vol. 12, no. 5, pp. 789-798, 2004.

[31] P. Ekkekakis, "Let them roam free?: physiological and psychological evidence for the potential of self-selected exercise intensity in public health," Sports Medicine, vol. 39, no. 10, pp. 857-888, 2009.

[32] W. McArdle, F. Katch, and V. Katch, Exercise Physiology: Nutrition, Energy and Human Performance, Lippincott, Williams \& Williams, Philadelphia, Pa, USA, 7th edition, 2010.

[33] J. J. Demello, K. J. Cureton, R. E. Boineau, and M. M. Singh, "Ratings of perceived exertion at the lactate threshold in trained and untrained men and women," Medicine and Science in Sports and Exercise, vol. 19, no. 4, pp. 354-362, 1987.

[34] X. Z. He and D. W. Baker, "Changes in weight among a nationally representative cohort of adults aged 51 to 61,1992 to 2000," American Journal of Preventive Medicine, vol. 27, no. 1, pp. 8-15, 2004.

[35] B. E. Ainsworth, W. L. Haskell, A. S. Leon et al., "Compendium of physical activities: classification of energy costs of human physical activities," Medicine and Science in Sports and Exercise, vol. 25, no. 1, pp. 71-80, 1993.

[36] S. N. Blair, H. W. Kohl, C. E. Barlow, R. S. Paffenbarger, L. W. Gibbons, and C. A. Macera, "Changes in physical fitness and all-cause mortality: a prospective study of healthy and unhealthy men," Journal of the American Medical Association, vol. 273, no. 14, pp. 1093-1098, 1995.

[37] J. Myers, M. Prakash, V. Froelicher, D. Do, S. Partington, and J. Edwin Atwood, "Exercise capacity and mortality among men referred for exercise testing," New England Journal of Medicine, vol. 346, no. 11, pp. 793-801, 2002.

[38] J. A. Pintar, R. J. Robertson, A. M. Kriska, E. Nagle, and F. L. Goss, "The influence of fitness and body weight on preferred exercise intensity," Medicine and Science in Sports and Exercise, vol. 38, no. 5, pp. 981-988, 2006.

[39] A. G. Huebschmann, E. N. Reis, C. Emsermann et al., "Women with type 2 diabetes perceive harder effort during exercise than nondiabetic women," Applied Physiology, Nutrition and Metabolism, vol. 34, no. 5, pp. 851-857, 2009.

[40] S. G. Dasilva, L. Guidetti, C. F. Buzzachera et al., "Psychophysiological responses to self-paced treadmill and overground exercise," Medicine and Science in Sports and Exercise, vol. 43, no. 6, pp. 1114-1124, 2011.

[41] J. F. Miller and B. A. Stamford, "Intensity and energy cost of weighted walking versus running for men and women," Journal of Applied Physiology, vol. 62, no. 4, pp. 1497-1501, 1987.

[42] C. Hall, A. Figueroa, B. Fernhall, and J. A. Kanaley, "Energy expenditure of walking and running: comparison with prediction equations," Medicine and Science in Sports and Exercise, vol. 36, no. 12, pp. 2128-2134, 2004.

[43] K. Parvataneni, L. Ploeg, S. J. Olney, and B. Brouwer, "Kinematic, kinetic and metabolic parameters of treadmill versus 
overground walking in healthy older adults," Clinical Biomechanics, vol. 24, no. 1, pp. 95-100, 2009.

[44] M. H. Murphy and A. E. Hardman, "Training effects of short and long bouts of brisk walking in sedentary women," Medicine and Science in Sports and Exercise, vol. 30, no. 1, pp. 152157, 1998. 


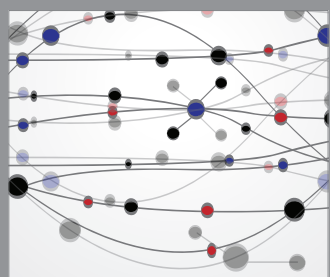

The Scientific World Journal
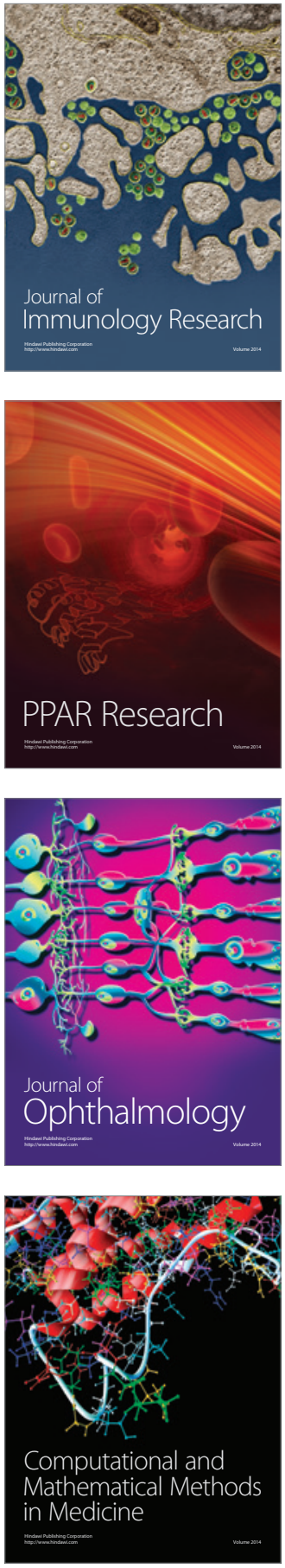

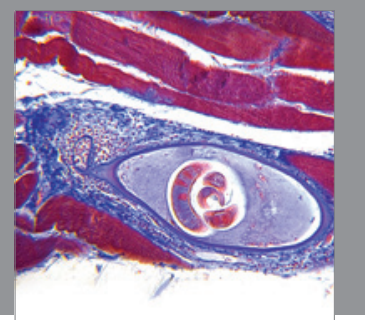

Gastroenterology

Research and Practice
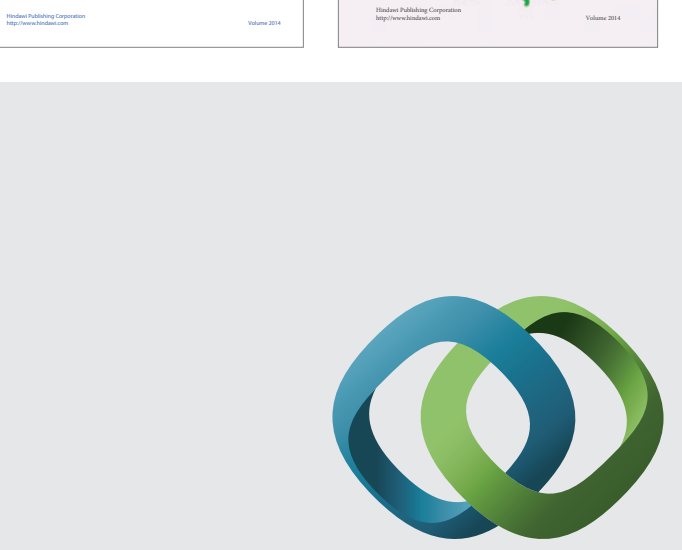

\section{Hindawi}

Submit your manuscripts at

http://www.hindawi.com
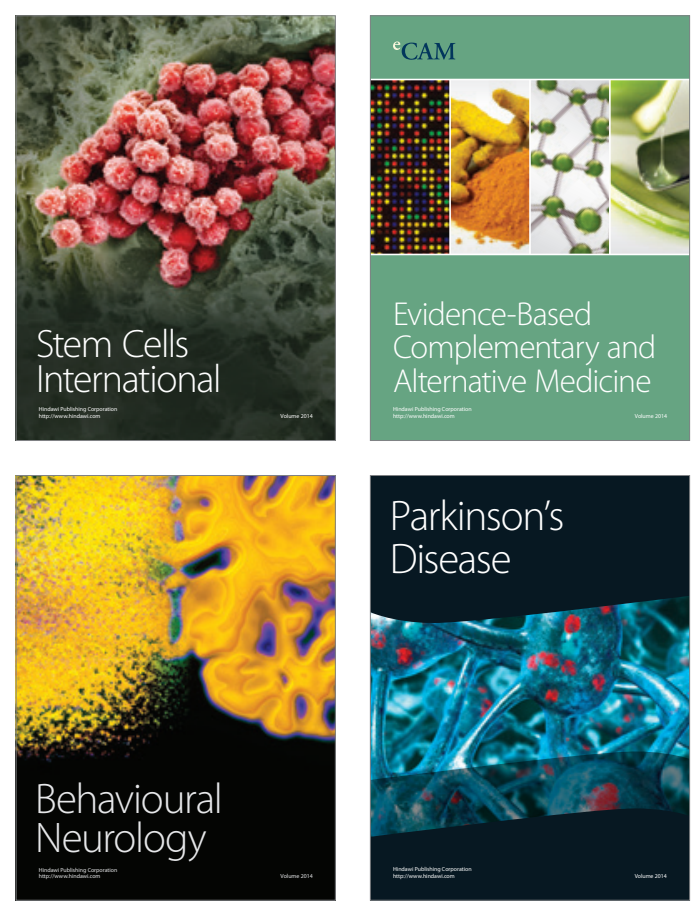

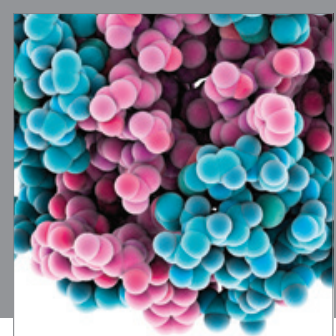

Journal of
Diabetes Research

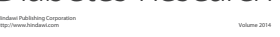

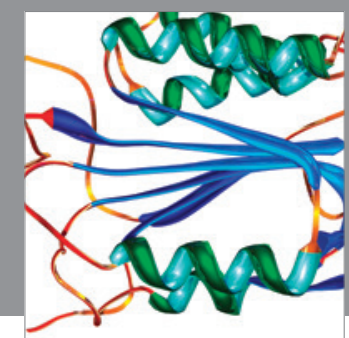

Disease Markers
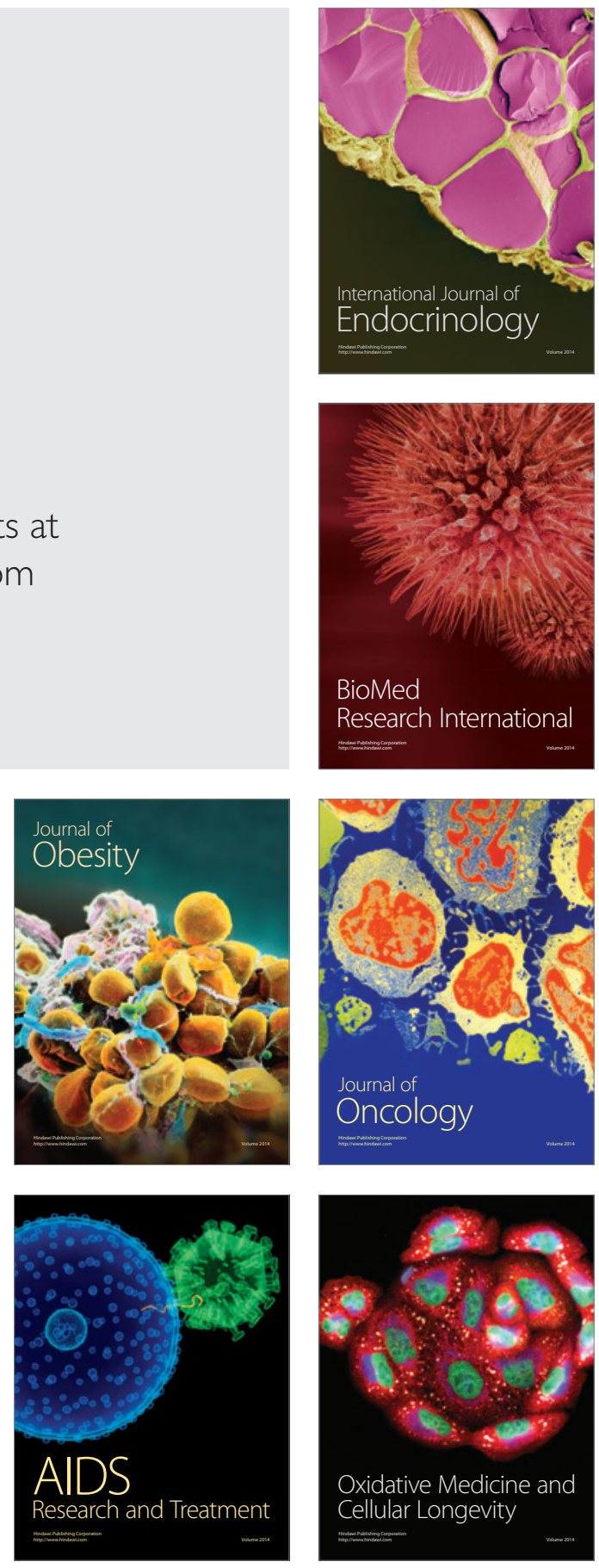